\section{Darwin for doctors}

\author{
John Launer
}

If you ask people to summarise the ideas of Charles Darwin, they are quite likely to say that he created the concept of 'survival of the fittest.' They may go on to explain this means that stronger individuals generally prevail over weaker ones, and similarly that stronger species will usually survive, while weaker ones usually do not do so well. Evolution, they may state, is the long term process by which increasingly stronger organisms emerge, while others go to the wall as a result of being too feeble. They may even assert that Darwin regarded human beings as the prime example of how creatures with superior intelligence will always triumph over those endowed with less mental ability.

As it happens, all these statements are wrong. Darwin never invented the phrase 'survival of the fittest.' It was coined by another Victorian, the political philosopher Herbert Spencer, who tried to apply evolutionary ideas to society in a way that is generally acknowledged to be flawed. Darwin himself never argued that strength was the most crucial factor in whether different types of individuals or species were preserved into the next generation. His own idea of 'fitness' bore little relation to the modern concept of going to the gym and building up muscles. Instead, he was talking about the way certain varieties of organism in each generation turned out to 'fit' the changing environment around them, while others were less fortunate because their attributes happened to be less suitable when an unpredictable shift occurred in the geography, climate or ecology around them. Rather than believing that there would always be inexorable progress towards better types of life, Darwin recognised that the natural world was a vast interactive system, where new and different forms will always emerge in a continual cycle of change. He made no special claims for 'homo sapiens' other than pointing out that our specific abilities had, for the time being at least, enabled us to colonise a wide range of habitats, although not of course as many as some other kinds of species including birds.

Correspondence to Dr John Launer, Faculty Development, Health Education North West London, Stewart House, 32 Russell Square, London WC1B 5DN, UK: john.launer@londondeanery.nhs.uk
It is probably quite common for people to misunderstand what great thinkers from the past have said, or to subscribe to dumbed down versions of this. In most cases - with Galileo or Einstein, for example - this matters little and is unlikely to do any harm. It the case of Darwin's ideas, it has at times been quite literally catastrophic. Herbert Spencer's erroneous view of evolution, which came to be known as 'social Darwinism', was used to provide intellectual justification for everything from the extermination of the Australian aboriginals to the Holocaust. It continues to dominate the views of many political and economic leaders, who are possessed with the conviction that the only way to achieve success is through aggressive competition rather than through an understanding of ecological processes - including the importance of mutual interdependence, and the risk that pursuing short term selfinterest may imperil long term survival.

\section{'BEING FIT' VERSUS FITNESS}

The confusion of these two different constructions of fitness -the Spencerian one of brute strength and the true Darwinian one of 'fitting the changing environment' - has had insidious effects in medicine as well. An obvious example is in people's attitudes to micro-organisms and infectious diseases. Here, we are guided by the naïve assumption that we are engaged in a winnable battle against vicious enemies, instead of needing to co-exist with a myriad of constantly evolving creatures who share our bodies in what is a generally harmonious fashion. Our conceptions of cancer, dominated by metaphors of war and victory, may be another example of such narrow and distorted thinking. In reality, a false or non-Darwinian notion of fitness pervades our thinking so much in medicine that we never even notice this. It even affects our understanding of 'fitness to practise medicine.' This is usually taken to signify a set of fixed competencies, when it might be better and more accurate to conceptualise it in terms of the ways that doctors need to adapt continually to the changing state of human knowledge and the social and political circumstances in which they work.

A subtler and more informed view of fitness could benefit medicine in many other ways as well. In a sense, every encounter with patients is an attempt to find a good 'fit' between what they are seeking and what we have to offer. This is true of each consultation. It is just as true of every small exchange of talk that takes place within every consultation. Indeed, it is possible to understand spoken language itself - not to mention body language, touch and other forms of communication - as unceasing attempts to respond to another's needs, and to adjust one's own reactions accordingly. Evolution, in other words, is not just something that happens from one generation to the next. It occurs in the momentary ways that we enhance our own survival, and the survival of those around us, by the tiniest calibration of our responses to others, and to the physical environment. It is also reflected in the physiological, cellular and molecular changes that accompany any such response.

\section{RECLAIMING FITNESS}

Darwin's view of fitness, in its original and authentic form, was a profoundly scientific one, connecting all the different forms of life with each other, through historical time and across the entire planet, as well as with the inanimate world of geology and climate. It was also, paradoxically, a deeply spiritual vision. (Without going into the contentious area of Darwin's own religious beliefs, it is worth pointing out that 'The Origin of Species' both begins and ends with references to divinity. ${ }^{1}$ ) Through its combination of rationality with - in its broadest sense - a religious perspective, it offers doctors a unifying concept for all the work we do, and all the different levels of knowledge that contribute to that work. If doctors were explicitly taught a true version of Darwinian thought, instead of implicitly absorbing a distorted one, I believe it could transform their understanding of everything from biochemistry to psychology, and of their own roles as healers. We need to reclaim a view of 'fitness' that is itself fit for purpose.

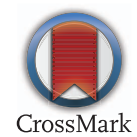

To cite Launer J. Postgrad Med J 2014;90:242.

Postgrad Med J 2014:90:242.

doi:10.1136/postgradmedj-2014-132670

\section{REFERENCE}

1 Darwin C. On the Origin of Species By Means of Natural Selection: Or, the Preservation of Favoured Races in the Struggle for Life. London: John Murray, 1859. 